\title{
Erratum to: Hygehos Ontology for Electronic Health Records
}

Naiara Muro, Eider Sanchez, Manuel Graña, Eduardo Carrasco, Fran Manzano, Jose María Susperregi, Agustin Agirre and Jesús Gómez

\section{Erratum to:}

Chapter "Hygehos Ontology for Electronic Health Records" in: Y.-W. Chen et al. (eds.), Innovation in Medicine and Healthcare 2016, Smart Innovation, Systems and Technologies 60, DOI 10.1007/978-3-319-39687-3_33

In the original version of the book, in Chap. 30, Figure 3 was affected and has to be replaced. The erratum chapter and the book have been updated with the change. 